\title{
Retention Rate and Safety of Biosimilar CT-P13 in Rheumatoid Arthritis: Data from the Korean College of Rheumatology Biologics Registry
}

\author{
Hyoun-Ah Kim ${ }^{1}$ (E) Eunyoung Lee ${ }^{2,3} \cdot$ Sun-Kyung Lee ${ }^{4}$ Yong-Beom Park ${ }^{5}$ Young Nam Lee ${ }^{6}$ • Hee Jung Kang ${ }^{6}$. \\ Kichul Shin ${ }^{4}$
}

Published online: 16 November 2019

(C) The Author(s) 2019

\begin{abstract}
Objective The aim was to evaluate long-term drug retention, discontinuation, efficacy and safety of CT-P13 and reference infliximab in patients with rheumatoid arthritis (RA) enrolled in the Korean College of Rheumatology Biologics (KOBIO) registry.

Methods Patients included adults with RA who received CT-P13 or reference infliximab between December 2012 and December 2017. Drug retention, efficacy (Disease Activity Score in 28 joints [DAS28]-erythrocyte sedimentation rate [ESR] or DAS28-C-reactive protein [CRP] and American College of Rheumatology [ACR] core set measure), and adverse events (AEs) were assessed over 4-years' follow-up.

Results Data from 199 RA patients (CT-P13: $n=147$; reference infliximab: $n=52)$ were analyzed. Median treatment duration was 1.22 years for CT-P13 and 1.40 years for reference infliximab $(p=0.67)$. Overall, $82 \%$ of patients received first-line therapy. Drug retention of CT-P13 versus reference infliximab was comparable for the overall population $(p=0.84)$ and for first-line $(p=0.66)$ and subsequent treatment lines $(p=0.96)$. Treatment changes or discontinuations occurred in $65.2 \%$ of patients with CT-P13 and $69.6 \%$ with reference infliximab. The most common reason for treatment changes or discontinuing treatment was lack of efficacy (CT-P13: 31.9\%; reference infliximab: 34.8\%). CT-P13 demonstrated comparable improvements in DAS28-ESR, DAS28-CRP and ACR responses to reference infliximab. Overall, 19 grade 3 AEs were reported for CT-P13 and eight for reference infliximab.

Conclusion Long-term data from patients with RA treated in routine clinical practice in Korea showed that CT-P13 had a comparable drug retention rate to reference infliximab, with similar efficacy and an acceptable safety profile.

ClinicalTrials.gov identifier NCT01965132.
\end{abstract}

\section{Introduction}

CT-P13, a chimeric monoclonal antibody against tumor necrosis factor (TNF), is a biosimilar of infliximab reference product [1]. CT-P13 was the first biosimilar monoclonal antibody to be approved by the European Medicines Agency in 2013 for the same indications as reference infliximab, including rheumatoid arthritis (RA) (in combination

Electronic supplementary material The online version of this article (https://doi.org/10.1007/s40259-019-00393-y) contains supplementary material, which is available to authorized users.

Kichul Shin

kideb1@gmail.com

Extended author information available on the last page of the article with methotrexate), ankylosing spondylitis, Crohn's disease, ulcerative colitis, psoriatic arthritis and psoriasis [1, 2]. As of July 2019, CT-P13 has been approved in 91 countries worldwide.

Supporting clinical evidence for the approval of CT-P13 came from two randomized clinical trials [3]: PLANETAS, involving patients with ankylosing spondylitis [4], and PLANETRA, involving RA patients with an inadequate response to methotrexate [5]. The PLANETAS [4, 6] and PLANETRA $[5,7]$ studies showed that CT-P13 and reference infliximab had equivalent pharmacokinetic profiles, comparable efficacy, and no clinically important differences in safety profiles up to week 54. In the PLANETRA extension study, comparable efficacy and tolerability were observed in those patients who switched from reference infliximab to CT-P13 for an additional year and in those 


\section{Key Points}

Patients with rheumatoid arthritis (RA) enrolled in the Korean College of Rheumatology Biologics (KOBIO) registry were managed according to routine clinical practice, providing a comprehensive and accurate real-world assessment.

Long-term data from the KOBIO registry showed that, in Korean patients with RA, CT-P13 had a comparable drug retention rate to reference infliximab, with similar efficacy and an acceptable safety profile.

The comparability of CT-P13 and reference infliximab with regard to safety, tolerability and efficacy, combined with the lower price of CT-P13, offers the opportunity for substantial cost-savings without compromising on quality of treatment or patient outcomes.

who received CT-P13 for 2 years [8]. Additional support regarding the comparable efficacy and safety of CT-P13 and reference infliximab comes from a randomized, double-blind trial in Japanese RA patients with an inadequate response to methotrexate [9]. Results from the extension phase of this study demonstrated that treatment with CT-P13, either longterm or after switching from reference infliximab, was well tolerated with persistent efficacy [10]. Furthermore, results from the 52-week randomized, double-blind, non-inferiority, phase IV NOR-SWITCH trial involving patients with a range of inflammatory diseases, including RA, demonstrated that switching to CT-P13 was not inferior to continued treatment with reference infliximab, with similar drug discontinuation rates [11].

As well as demonstrating the equivalence of CT-P13 and reference infliximab under clinical study conditions, it is important to show that long-term patient outcomes are comparable in the real-world clinical setting. Several real-world studies have shown that the efficacy and safety of CT-P13 are maintained during long-term treatment in patients with inflammatory rheumatologic diseases, including RA [12-17]. Although data from the DANBIO registry showed that the adjusted 1-year retention rate of CT-P13 was slightly lower than reference infliximab in a historic cohort, this difference may represent a nocebo effect [15], where patients can have worsening symptoms induced by a negative attitude towards an intervention (including switching to a biosimilar) [18]. In a recent real-life study of patients with rheumatic disease who had switched from reference infliximab to CT-P13, comparison with a historic reference infliximab cohort revealed an initial nocebo effect [14]. However, with longer follow-up, retention rates of reference infliximab and CT-P13 appeared to be identical, which confirms the safety, efficacy and acceptability of switching in the long-term [14]. These findings highlight the need for long-term follow-up data in real-world studies.

The Korean College of Rheumatology Biologics (KOBIO) registry is an ongoing, multi-center, prospective, observational study designed to collect real-world data on patients being treated with biologic disease-modifying antirheumatic drugs (DMARDs) in Korea [19-21]. The aim of this analysis from the KOBIO registry was to evaluate drug retention rates, discontinuations, efficacy and safety of CT-P13 and reference infliximab in Korean patients with RA who were followed for up to 4 years. In addition, we also investigated outcomes in patients receiving CT-P13 or reference infliximab as first-line or subsequent therapy.

\section{Materials and Methods}

\subsection{Study Population}

Data were collected through $\mathrm{KOBIO}$, a nationwide registry in Korea established in December 2012 to capture data on the use of biologic agents (ClinicalTrials.gov identifier: NCT01965132) [21]. The KOBIO registry was established as an inception cohort, enrolling patients with a diagnosis of RA, ankylosing spondylitis or psoriatic arthritis at the time of initiating, restarting or changing a biologic [19-21].

Patients aged $\geq 18$ years were eligible for inclusion in the KOBIO registry if they had RA that required treatment with a biologic or non-biologic DMARD, as deemed by their rheumatologist [21]. Patients already on biologic therapy at screening were excluded from the registry. Participation in the registry did not require any additional visits or laboratory tests outside routine clinical practice.

This analysis presents data from patients with RA who had received CT-P13 or reference infliximab, concurrent with methotrexate per the label, between December 2012 and December 2017. Patients were excluded from this analysis if they did not receive treatment with CT-P13 or reference infliximab.

All patient treatments were determined by the treating physician, including the selection of biologic, dosing and treatment duration. The present analysis was conducted according to the principles of the Declaration of Helsinki. All patients provided written consent to participate in the registry, and the data collection form and study protocol were approved by institutional review boards (Ajou University Hospital; AJIRB-MED-MDB-17-505) or local ethics committees at each participating center. 


\subsection{Data Collection and Outcomes Measured}

Data were collected annually from participating hospitals using standardized case report forms. The following baseline data were collected for this analysis: age, gender, body mass index, smoking history, disease duration, disease activity, erythrocyte sedimentation rate (ESR), C-reactive protein (CRP), rheumatoid factor positivity, anti-cyclic citrullinated peptide positivity, previous DMARD use, corticosteroid use and line of therapy.

The primary outcome measure for this analysis was drug retention (i.e., time to treatment discontinuation or changing to another biologic). Data were collected on treatment dates and lines of therapy, treatment changes and reasons for changing, and discontinuations and reasons for discontinuation. Discontinuation was defined as permanent discontinuation of biologic therapy.

Efficacy was assessed using the Disease Activity Score in 28 joints (DAS28)-ESR or DAS28-CRP score, and the American College of Rheumatology (ACR) core set measure. The response rates were reported using per-protocol analysis. The DAS28 scale ranges from 0 to 9.4 , where a score $<2.6$ indicates remission, $\geq 2.6$ to $<3.2$ low disease activity, $\geq 3.2$ to $\leq 5.1$ moderate disease activity, and $>5.1$ highly active disease [22]. ACR20 indicates a $20 \%$ improvement in both tender and swollen joint counts and three out of five other measures within the ACR core set of disease activity measures [23]. ACR50 and ACR70 correspond to 50\% and $70 \%$ improvement, respectively. The number of patients with adverse events (AEs), defined using the Medical Dictionary for Regulatory Activities (version 17.0), during treatment with biologics was evaluated. AEs were also assessed after changing biologic or after discontinuation of biologic therapy. Those patients who did not have a documented time to discontinuation were included in the analyses of baseline demographics, efficacy and safety, but were excluded from analysis of drug retention rate.

\subsection{Statistical Analyses}

Drug retention rates were analyzed using Kaplan-Meier survival curves and were compared statistically using a log-rank test. Confidence bands were calculated using the method of Hall and Wellner [24]. Baseline demographics and disease characteristics were compared between treatment groups using a Chi squared test of homogeneity for categorical variables and $t$ test for continuous variables. Efficacy measured by DAS28 score was compared statistically with $p$ values calculated using a two-sided Wilcoxon rank-sum test. All statistical analyses were performed using SAS statistical software (version 9.4, SAS Institute), and $p$ values $<0.05$ were considered statistically significant.

\section{Results}

\subsection{Patient Characteristics}

Data from 199 patients with RA enrolled in the KOBIO registry between December 2012 and December 2017 were analyzed, of whom 147 patients were treated with CT-P13 and 52 patients with reference infliximab. Data are presented for the number of enrolled patients, although missing data, such as ESR, CRP or questionnaire answers meant that for some parameters, data were not available for all patients. In addition, 12 patients treated with CT-P13 and eight patients treated with reference infliximab were lost to follow-up and were excluded from some analyses.

Patient baseline demographics and characteristics were similar between groups (Table 1). Patients had a mean age of 51.8 years [standard deviation $(\mathrm{SD}) \pm 12.2$ years]. Mean DAS28-CRP (5.0, SD \pm 1.2$)$ and DAS28-ESR (5.7, $\mathrm{SD} \pm 1.1)$ scores at baseline were consistent with a patient population with moderate-to-severely active RA [22]. The mean duration of disease at baseline was 7.4 years ( $\mathrm{SD} \pm 7.6$ years), indicative of a patient population with long-established RA. At baseline, almost all patients (96.5\%) had been previously treated with DMARDs and concurrent corticosteroid use was reported in $87.9 \%$ of patients. The majority of patients $(82.4 \%)$ received first-line infliximab therapy (CT-P13: $n=124 / 147,84.4 \%$; reference infliximab: $n=40 / 52,76.9 \%$ ), with second or subsequent lines of therapy received by $17.6 \%$ of patients (CT-P13: $n=23 / 147$, $15.6 \%$; reference infliximab: $n=12 / 52,23.1 \%$ ).

\subsection{Treatment Duration and Drug Retention}

Treatment duration is shown in Supplementary Table 1 (see the electronic supplementary material, Online Resource 1). Overall, the median duration of treatment was 1.22 years (range 0.54-2.31) with CT-P13 and 1.40 years (range $0.43-3.16$ ) with reference infliximab $(p=0.67)$. Irrespective of treatment group, duration of first-line therapy was longer than subsequent lines of therapy (Supplementary Table 1 in Online Resource 1). The median treatment duration in patients receiving first-line or subsequent CT-P13 therapy was 1.32 (range 0.58-2.47) and 0.83 years (range $0.35-1.97$ ), respectively, and in those receiving first-line or subsequent reference infliximab therapy, it was 1.65 (range $0.43-3.16$ ) and 0.58 years (range 0.42-3.42), respectively.

Overall, there was no difference in drug retention with CT-P13 and reference infliximab (log-rank $p=0.84$; Fig. 1a). Drug retention was also similar between CT-P13 and reference infliximab groups in patients who received first-line therapy ( $p=0.66$; Fig. $1 \mathrm{~b}$ ) and subsequent treatment lines 
Table 1 Baseline patient characteristics

\begin{tabular}{|c|c|c|c|c|}
\hline Characteristic & All patients $(N=199)$ & CT-P13 $(N=147)$ & $\begin{array}{l}\text { Reference infliximab } \\
(N=52)\end{array}$ & $P$ value \\
\hline Age, years & $51.8(12.2)$ & $51.3(12.4)$ & $53.3(11.5)$ & 0.30 \\
\hline Disease duration, years & $7.4(7.6)$ & $7.7(7.6)$ & $6.5(7.7)$ & 0.35 \\
\hline Male, $n(\%)$ & $28(14.1)$ & $18(12.2)$ & $10(19.2)$ & 0.21 \\
\hline BMI, $\mathrm{kg} / \mathrm{m}^{2}$ & $22.9(4.0)$ & $23.0(4.2)$ & $22.8(3.3)$ & 0.75 \\
\hline Smoking history, $n(\%)$ & & & & 0.55 \\
\hline Ex-smoker & $13(6.5)$ & $9(6.1)$ & $4(7.7)$ & - \\
\hline Current smoker & $14(7.0)$ & $12(8.2)$ & $2(3.8)$ & - \\
\hline Never & $172(86.4)$ & $126(85.7)$ & $46(88.5)$ & - \\
\hline Tender joint count & $9.9(8.2)$ & $9.9(7.5)$ & $9.8(10.1)$ & 0.92 \\
\hline Swollen joint count & $7.5(6.2)$ & $7.7(5.9)$ & $6.9(7.2)$ & 0.45 \\
\hline $\mathrm{ESR}, \mathrm{mm} / \mathrm{h}$ & $52.6(27.4)$ & $53.8(28.1)$ & $49.1(25.3)$ & 0.29 \\
\hline CRP, mg/dL & $2.9(5.3)$ & $3.1(6.0)$ & $2.4(2.4)$ & 0.24 \\
\hline DAS28-ESR & $5.7(1.1)$ & $5.7(1.2)$ & $5.5(1.1)$ & 0.29 \\
\hline DAS28-CRP & $5.0(1.2)$ & $5.0(1.2)$ & $4.9(1.1)$ & 0.43 \\
\hline Rheumatoid factor (positivity), $n(\%)$ & $163(81.9)$ & $117(79.6)$ & $46(88.5)$ & 0.12 \\
\hline Anti-CCP (positivity), $n(\%)$ & $139(69.8)$ & $99(67.3)$ & $40(76.9)$ & 0.055 \\
\hline Previous DMARD use, $n(\%)$ & $192(96.5)$ & $142(96.6)$ & $50(96.2)$ & 0.88 \\
\hline Methotrexate dose, mg/week, median (IQR) & $15(10-15)$ & $15(12.5-15)$ & $15(10-15)$ & 0.59 \\
\hline Corticosteroid use, $n(\%)$ & 175 (87.9) & $127(86.4)$ & $48(92.3)$ & 0.26 \\
\hline $\begin{array}{l}\text { Corticosteroid dose, dose equivalent for predniso- } \\
\text { lone in mg/day, median (IQR) }\end{array}$ & $5(2.5-7.5)$ & $5(2.5-7.5)$ & $6(4-8)$ & 0.013 \\
\hline Infliximab treatment line, $n(\%)$ & & & & 0.23 \\
\hline 1st line & $164(82.4)$ & $124(84.4)$ & $40(76.9)$ & - \\
\hline$\geq 2$ nd line & 35 (17.6) & $23(15.6)$ & $12(23.1)$ & - \\
\hline
\end{tabular}

Data presented are mean (standard deviation), unless otherwise indicated

$B M I$ body mass index, $C C P$ cyclic citrullinated peptide, $C R P$ C-reactive protein, DAS28 disease activity score in 28 joints, DMARD diseasemodifying antirheumatic drug, $E S R$ erythrocyte sedimentation rate, $I Q R$ interquartile range

( $p=0.96$; Fig. 1c). After 4 years' follow-up, the retention rate was $17.5 \%$ for CT-P13 and $33.6 \%$ for reference infliximab in the overall patient population. In patients receiving first-line therapy, the retention rate was $15.7 \%$ for CT-P13 and $35.4 \%$ for reference infliximab.

\subsection{Treatment Changes and Discontinuations}

Reasons for changing to another agent or discontinuing treatment are presented in Table 2. Overall, the rate of treatment changes or discontinuations was similar between the CT-P13 and reference infliximab groups $(65.2 \%$ vs $69.6 \%$, respectively). The most common reason for treatment changes or discontinuations was lack of efficacy (CT-P13: 31.9\%; reference infliximab: $34.8 \%$ ). Treatment changes or discontinuations due to an $\mathrm{AE}$ were reported in $20.0 \%$ of patients in the CT-P13 group and $23.9 \%$ of patients in the reference infliximab group. A similar proportion of patients in the CT-P13 group and reference infliximab groups changed or discontinued therapy after achieving clinical remission (3.0\% and $4.3 \%$, respectively).

A similar proportion of patients in each treatment group changed biologic therapy (CT-P13: 43.7\%; reference infliximab: $39.1 \%$ ) or discontinued treatment (CT-P13: 21.5\%; reference infliximab: $30.4 \%$; Table 2). Of those patients who changed biologic therapy in the CT-P13 and reference infliximab groups, the most commonly cited reason was lack of efficacy (Table 2). AEs were the most commonly cited reason for discontinuing treatment with CT-P13 or reference infliximab (Table 2). AEs leading to treatment discontinuation or changing to another biologic are shown in Supplementary Table 2 (Online Resource 1). Infusionrelated reactions were the most common AEs resulting in treatment changes (CT-P13: 12 events; reference infliximab: two events) and treatment discontinuation (CT-P13: three events; reference infliximab: three events).

Similar proportions of patients receiving first-line CT-P13 or reference infliximab changed biologic $(44.2 \%$ and $42.9 \%$, 
(a)

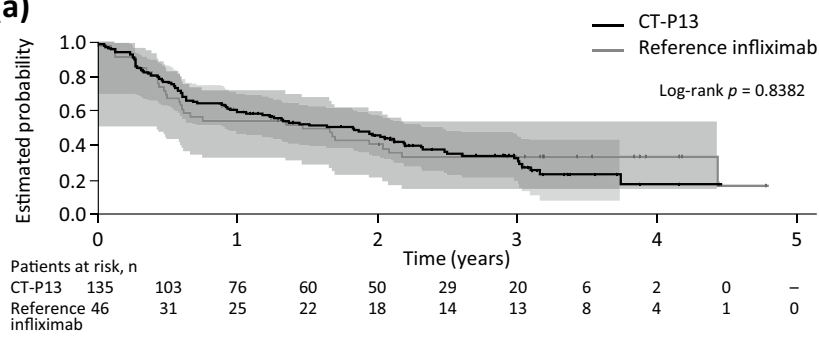

(b)

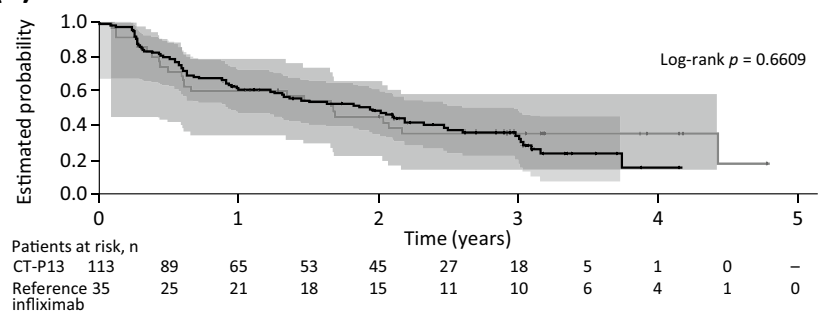

(c)

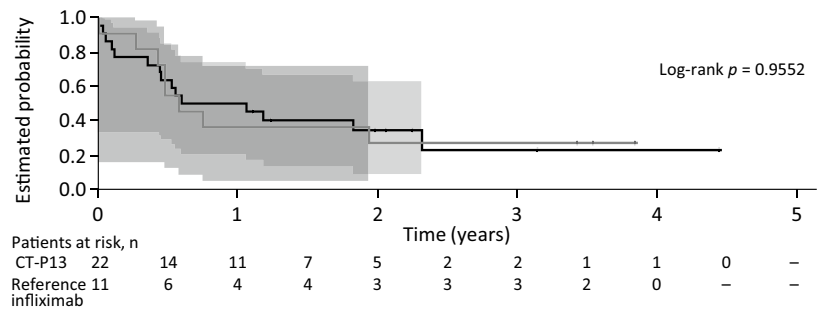

Fig. 1 Drug retention in a all patients, b patients treated with firstline therapy and c patients treated with second-line or subsequent therapy. Shading indicates 95\% Hall-Wellner bands. + indicates censored patients

respectively) or discontinued treatment ( $20.4 \%$ and $22.9 \%$, respectively; Supplementary Table 3, Online Resource 1). Reasons for discontinuing treatment or changing to another biologic by line of therapy are presented in Supplementary Table 3 (Online Resource 1). Overall, 15 out of 22 patients $(68.2 \%)$ in the CT-P13 group and nine out of 11 patients $(81.8 \%)$ in the reference infliximab group changed or discontinued treatment during second-line or subsequent therapy.

The drugs received following treatment with CT-P13 and reference infliximab are summarized in Supplementary Table 4 (Online Resource 1). Tocilizumab was the most commonly substituted drug following first-line treatment with CT-P13 and reference infliximab $(34.0 \%$ and $73.3 \%$, respectively). Adalimumab was also commonly used following first-line treatment with CT-P13 (26.0\%), but was not substituted after first-line reference infliximab.

\subsection{Efficacy}

CT-P13 demonstrated similar efficacy to reference infliximab with comparable improvements observed over time (Figs. 2 and 3). Over the 4-year observation period, treatment with either CT-P13 or reference infliximab resulted in a substantial reduction in disease activity from baseline, assessed by DAS28-ESR and DAS28-CRP (Fig. 2). After 2 years of treatment with either CT-P13 or reference infliximab, DAS28-ESR and DAS28-CRP scores corresponded to low disease activity/disease remission, and disease control was maintained up to 4 years after initiating treatment. ACR20 response rates in the first year of treatment were $57.3 \%$ with CT-P13 and $45.8 \%$ with reference infliximab, and increased in the second year of treatment (CT-P13: 82.1\%; reference infliximab: $62.1 \%$; Fig. 3). ACR50 and ACR70 response rates showed a pattern consistent with ACR20 responses, where the proportion of patients responding increased between the first and second years of treatment and were numerically higher in the CT-P13 group compared with the reference infliximab group (Fig. 3).

Table 2 Reasons for discontinuation of therapy or changing to another biologic

\begin{tabular}{|c|c|c|c|c|c|c|}
\hline & \multicolumn{3}{|l|}{ CT-P13 $(N=135)$} & \multicolumn{3}{|c|}{ Reference infliximab $(N=46)$} \\
\hline & Changed, $n(\%)$ & $\begin{array}{l}\text { Discontinued treat- } \\
\text { ment, } n(\%)\end{array}$ & Total, $n(\%)$ & Changed, $n(\%)$ & $\begin{array}{l}\text { Discontinued treat- } \\
\text { ment, } n(\%)\end{array}$ & Total, $n(\%)$ \\
\hline Lack of efficacy & $35(25.9)$ & $8(5.9)$ & $43(31.9)$ & $14(30.4)$ & $2(4.3)$ & $16(34.8)$ \\
\hline $\mathrm{AE}$ & $18(13.3)$ & $9(6.7)$ & $27(20.0)$ & $4(8.7)$ & $7(15.2)$ & $11(23.9)$ \\
\hline Clinical remission & - & $4(3.0)$ & $4(3.0)$ & - & $2(4.3)$ & $2(4.3)$ \\
\hline Other reasons & $6(4.4)^{\mathrm{a}}$ & $8(5.9)^{\mathrm{b}}$ & $14(10.4)$ & - & $2(4.3)^{\mathrm{c}}$ & $2(4.3)$ \\
\hline Unspecified & - & - & - & - & $1(2.2)$ & $1(2.2)$ \\
\hline Total & $59(43.7)$ & $29(21.5)$ & $88(65.2)$ & $18(39.1)$ & $14(30.4)$ & $32(69.6)$ \\
\hline
\end{tabular}

$A E$ adverse event

${ }^{a}$ Reasons include removal of prescription code for CT-P13 $(n=6)$

${ }^{\mathrm{b}}$ Reasons include patient's decision $(n=5)$, planning for pregnancy $(n=2)$ and scheduled surgery $(n=1)$

${ }^{c}$ Reasons include patient's decision $(n=1)$ and planning for pregnancy $(n=1)$ 


\subsection{Safety}

Overall, 19 grade 3 AEs were reported in the CT-P13 group and eight in the reference infliximab group (Table 3 ). There were four grade 3 AEs considered to be related to CT-P13 (one infusion/injection reaction; one infection, not specified; one case of mononeuritis multiplex; and one case of skin rash). No drug-related grade 3 AEs were reported with reference infliximab. Infusion-related reactions were the most commonly reported AEs (CT-P13: 16 events; reference infliximab: seven events), followed by infection (CT-P13: 11 events; reference infliximab: four events). There were no cases of tuberculosis reported with either treatment. Two cases of malignant solid tumors (one case of malignant

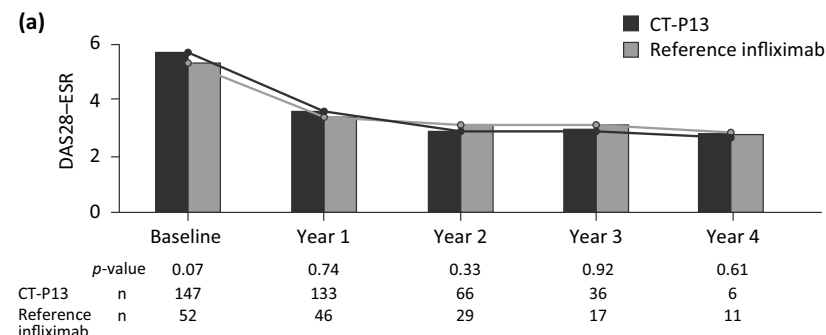

(b)

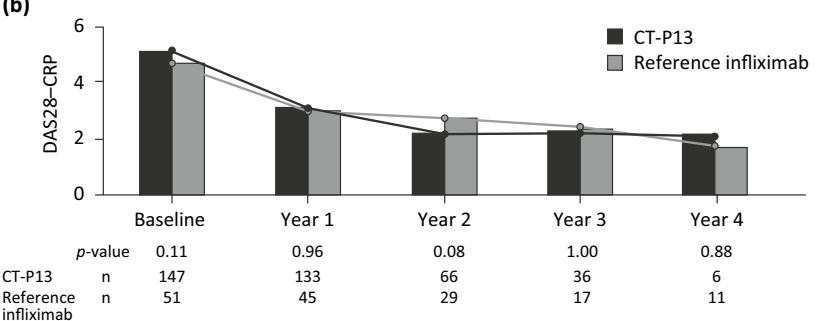

Fig. 2 Efficacy measured by a DAS28-ESR and b DAS28-CRP scores. DAS28-CRP disease activity score in 28 joints-C-reactive protein, DAS28-ESR disease activity score in 28 joints-erythrocyte sedimentation rate melanoma and one case of thyroid cancer) were reported with CT-P13. Three cases of malignancy (one case of lymphoma and two cases of oral cavity mass) were reported with reference infliximab. Of these malignancies, only lymphoma was deemed related to treatment. One death was reported in each group, due to pneumonia (CT-P13 group) and cardiac arrest (reference infliximab group).

\section{Discussion}

This prospective, registry-based, observational study presents real-life data on the long-term retention, efficacy and safety of CT-P13 compared with reference infliximab in Korean patients with RA. Our analysis showed that drug retention was comparable in patients treated with CT-P13 and reference infliximab, irrespective of treatment line. CT-P13 provided similar long-term clinical benefit to reference infliximab. Treatment with both CT-P13 and reference infliximab resulted in a substantial reduction in DAS28ESR and DAS28-CRP scores over the 4-year observation period. Furthermore, DAS28-ESR and DAS28-CRP scores

Table 3 Summary of adverse events of interest

\begin{tabular}{lcl}
\hline AE, number of events & $\begin{array}{l}\text { CT-P13 } \\
(N=147)\end{array}$ & $\begin{array}{l}\text { Reference } \\
\text { infliximab } \\
(N=52)\end{array}$ \\
\hline AE, grade 3 & 19 & 8 \\
Drug-related AE, grade 3 & 4 & 0 \\
Infusion-related reaction & 16 & 7 \\
Infection & 11 & 4 \\
Tuberculosis & 0 & 0 \\
Malignancy & 2 & 3
\end{tabular}

$A E$ adverse event
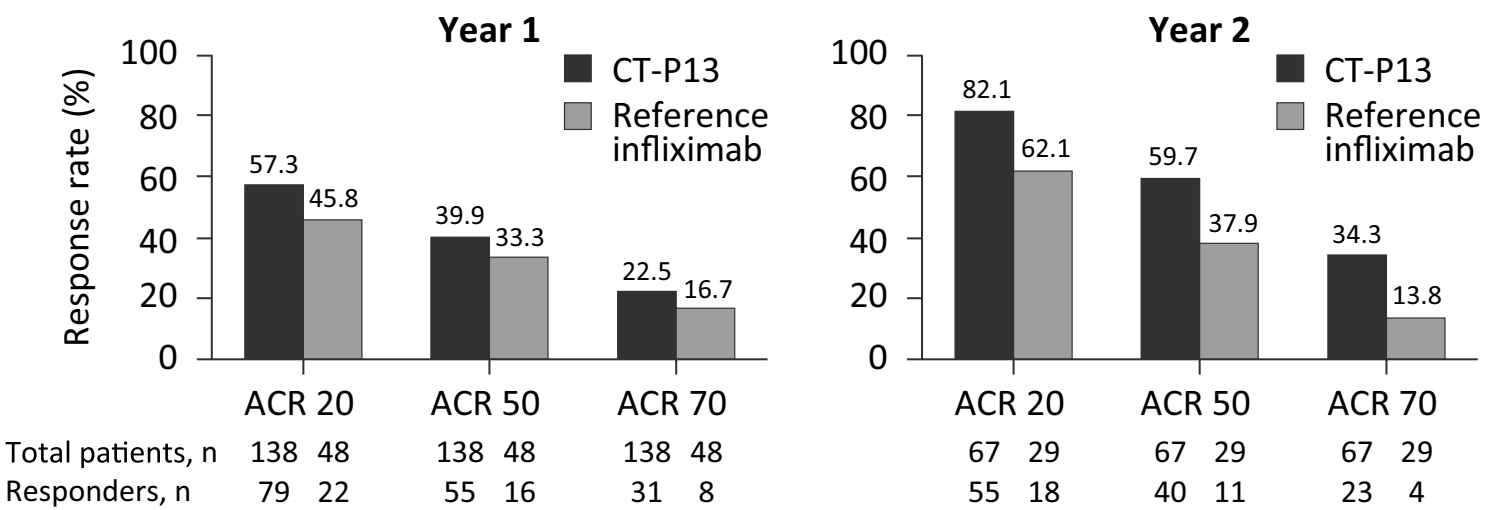

Fig. 3 ACR response by duration of follow-up. ACR American College of Rheumatology, ACR20 20\% response as defined by ACR, ACR50 50\% response as defined by ACR, ACR70 70\% response as defined by ACR 
corresponded to low disease activity/disease remission after 2 years of treatment with either CT-P13 or reference infliximab, and disease control was maintained up to 4 years after initiating treatment.

For observational registries, drug survival may be regarded as a reliable indicator of overall treatment effectiveness [25]. Registry-based studies in patients with RA who received first-line reference infliximab, including the Swedish Biologics Register ARTIS [26] and a local Italian registry [25], have reported drug survival rates of 38-44.3\% after 5 years. The Danish DANBIO registry reported a drug survival rate of $41 \%$ for reference infliximab after 2 years [27]. The reference infliximab retention rates found in our study were similar to previous reports, with a retention rate of $33.6 \%$ in the overall patient population and $35.4 \%$ in patients receiving first-line therapy, after 4 years' follow-up. The main reason for drug discontinuation in the observational registry studies was lack of efficacy and AEs [25-27], which is consistent with our study. Our analysis demonstrated that drug retention was comparable in patients treated with CT-P13 and reference infliximab irrespective of treatment line. This is consistent with the data reported by Germain et al., who observed similar treatment retention rates among patients with rheumatic disease who had switched from reference infliximab to CT-P13 (56\%, median follow-up 120 weeks), compared with a historic reference infliximab cohort (67\%, median follow-up 131 weeks; $p=0.052$ ) [14].

In the current study, the efficacy of CT-P13 and reference infliximab (in combination with methotrexate) was comparable when measured using the continuous disease activity measure of DAS28 and the dichotomous measure of ACR20 response in a patient population with highly active disease of long duration. We observed 1-year ACR20 response rates of $57.3 \%$ and $45.8 \%$ with CT-P13 and reference infliximab, respectively. Similarly, the PLANETRA randomized controlled study showed that CT-P13 and reference infliximab were comparable in terms of efficacy, although higher ACR20 response rates of $74.7 \%$ and $71.3 \%$ were achieved after 54 weeks of combined treatment with methotrexate plus CT-P13 or reference infliximab, respectively [7]. These higher response rates may reflect the fact that clinical trials have strict inclusion criteria and enrolled patients may not always be representative of the entire real-world patient population. Indeed, analysis of data from the German RABBIT registry has shown that only $21-33 \%$ of patients with RA treated with reference infliximab in RABBIT would have been eligible for major trials, with ineligible patients having lower response rates but similar absolute improvement [28].

CT-P13 was well tolerated during our study and displayed a long-term safety profile consistent with that of reference infliximab, with no clinically important differences. Consistent with the 54-week PLANETRA phase 3 clinical study [7], infusion-related reactions were the most commonly reported AEs in our analysis (CT-P13: 16 events; reference infliximab: seven events). Although it is established that patients with RA are at an increased risk of lymphoma compared with the general population, TNF inhibitor (TNFi) treatment does not appear to increase lymphoma risk [29-31]. The case of lymphoma deemed to be related to CT-P13 reported in our analysis does not raise safety concerns due to the known increased risk of lymphoma in patients with RA; however, the incidence of lymphoma in patients treated with TNFis should continue to be closely monitored. TNFis are associated with an increased risk of serious infections in RA [31], and infections are the most common serious AEs associated with CT-P13 and reference infliximab during post-marketing spontaneous reporting $[32,33]$. In the current study, one serious infection was reported in the CT-P13 group (pneumonia). Reassuringly, this study reported no cases of active tuberculosis infection with either infliximab product.

In addition to offering efficacy and safety comparable with reference infliximab, the introduction of CT-P13 for the treatment of RA offers the potential for substantial costsavings, given the high contribution of medication to overall treatment costs for RA [34, 35]. Introduction of lower-priced infliximab biosimilars, including CT-P13, might increase patient access to treatment, particularly in those countries where reference infliximab is not recommended due to cost constraints [35-37]. In addition, the NOR-SWITCH study has provided support for non-medical switching from reference infliximab to CT-P13 [11, 38]. In 2014, the Norwegian health authorities recommended CT-P13 for patients initiating infliximab treatment; as a result, the cost saving in Norway for CT-P13 versus reference infliximab increased from 39\% in 2014 to $69 \%$ in 2015 [11]. Such cost savings could significantly impact CT-P13 uptake and, consequently, healthcare budgets in many countries [11,38]. Direct medical costs for both patients and the payer were reduced following the introduction of biosimilar infliximab in the South Korean healthcare market, which could potentially be used to increase patient access to biologics [39]. Moreover, the introduction of infliximab biosimilars in the United Kingdom resulted in substantial cost-savings in the first 2 years of use [40], and considerable budget reductions are predicted for the roll out of infliximab biosimilars in other European countries [35, 41]. While treatment with intravenous CT-P13 is effective and well tolerated, a subcutaneous formulation of CT-P13 is being developed for self-administration [42, 43], offering the potential for improved patient compliance and reduced costs to healthcare systems [44].

Through the KOBIO registry, patients were managed according to routine clinical practice, providing a comprehensive and accurate real-world assessment. Strengths of our analysis include the prospective nature of data collection in the KOBIO registry, the long follow-up period, and the 
relatively large patient population. The main limitation of the current study is related to its observational design, which relies on passive reporting of safety events and may lead to under-estimation of incidence. Few patients included in this analysis received infliximab as second-line or subsequent therapy, precluding analysis of the reasons for discontinuing therapy in this population. Furthermore, the generalizability of our results to other countries may be influenced by the stringent Korean National Health Insurance reimbursement criteria for TNFi eligibility [45]; hence, the patient population in this analysis may not be representative of patient populations undergoing infliximab treatment in other countries and, subsequently, outcomes may vary.

\section{Conclusion}

In conclusion, long-term data from this nationwide cohort of Korean patients with RA treated in routine clinical practice showed that CT-P13 had a comparable drug retention rate to reference infliximab, with similar efficacy and an acceptable safety profile. The proven comparability of CT-P13 and reference infliximab safety, tolerability and efficacy, and the lower price of CT-P13, offers the opportunity for substantial cost-savings without compromising on quality of treatment or patient outcomes.

Acknowledgements Medical writing support (including development of a draft outline and subsequent drafts in consultation with the authors, assembling tables and figures, collating author comments, copyediting, fact checking and referencing) was provided by Julianna Solomons, $\mathrm{PhD}$, at Aspire Scientific (Bollington, UK), and funded by Celltrion Healthcare Co., Ltd. (Incheon, Republic of Korea).

Author contributions HAK, EL, YNL, HJK, and KS made a substantial contribution to the conception or design of the study; and all authors made a substantial contribution to the acquisition, analysis, and interpretation of the data and manuscript development, and gave final approval of the manuscript for submission.

\section{Compliance with Ethical Standards}

Funding This study was supported by Celltrion Healthcare Co., Ltd.

Conflict of interest Young Nam Lee and Hee Jung Kang are employees of Celltrion Healthcare Co., Ltd. Hyoun-Ah Kim, Eunyoung Lee, Sun-Kyung Lee, Yong-Beom Park, and Kichul Shin have no conflicts to declare.

Research including human participants The present analysis was conducted according to the principles of the Declaration of Helsinki. The data collection form and study protocol were approved by institutional review boards (Ajou University Hospital; AJIRB-MED-MDB-17-505) or local ethics committees at each participating center.

Informed consent All patients provided written consent to participate in the registry.
Data availability statement All available data are reported in the manuscript and supplementary file.

Open Access This article is distributed under the terms of the Creative Commons Attribution-NonCommercial 4.0 International License (http://creativecommons.org/licenses/by-nc/4.0/), which permits any noncommercial use, distribution, and reproduction in any medium, provided you give appropriate credit to the original author(s) and the source, provide a link to the Creative Commons license, and indicate if changes were made.

\section{References}

1. European Medicines Agency. European Public Assessment Report: Remsima. 2013. https://www.ema.europa.eu/docum ents/assessment-report/remsima-epar-public-assessment-repor t_en.pdf. Accessed 05 Feb 2019.

2. McKeage K. A review of CT-P13: an infliximab biosimilar. BioDrugs. 2014;28(3):313-21.

3. Becciolini A, Raimondo MG, Crotti C, Agape E, Biggioggero M, Favalli EG. A review of the literature analyzing benefits and concerns of infliximab biosimilar CT-P13 for the treatment of rheumatologic diseases: focus on interchangeability. Drug Des Devel Ther. 2017;11:1969-78.

4. Park W, Hrycaj P, Jeka S, Kovalenko V, Lysenko G, Miranda P, et al. A randomised, double-blind, multicentre, parallel-group, prospective study comparing the pharmacokinetics, safety, and efficacy of CT-P13 and innovator infliximab in patients with ankylosing spondylitis: the PLANETAS study. Ann Rheum Dis. 2013;72(10):1605-12.

5. Yoo DH, Hrycaj P, Miranda P, Ramiterre E, Piotrowski M, Shevchuk $\mathrm{S}$, et al. A randomised, double-blind, parallel-group study to demonstrate equivalence in efficacy and safety of CT-P13 compared with innovator infliximab when coadministered with methotrexate in patients with active rheumatoid arthritis: the PLANETRA study. Ann Rheum Dis. 2013;72(10):1613-20.

6. Park W, Yoo DH, Jaworski J, Brzezicki J, Gnylorybov A, Kadinov $\mathrm{V}$, et al. Comparable long-term efficacy, as assessed by patientreported outcomes, safety and pharmacokinetics, of CT-P13 and reference infliximab in patients with ankylosing spondylitis: 54-week results from the randomized, parallel-group PLANETAS study. Arthritis Res Ther. 2016;18:25.

7. Yoo DH, Racewicz A, Brzezicki J, Yatsyshyn R, Arteaga ET, Baranauskaite A, et al. A phase III randomized study to evaluate the efficacy and safety of CT-P13 compared with reference infliximab in patients with active rheumatoid arthritis: 54-week results from the PLANETRA study. Arthritis Res Ther. 2016;18:82.

8. Yoo DH, Prodanovic N, Jaworski J, Miranda P, Ramiterre E, Lanzon A, et al. Efficacy and safety of CT-P13 (biosimilar infliximab) in patients with rheumatoid arthritis: comparison between switching from reference infliximab to CT-P13 and continuing CT-P13 in the PLANETRA extension study. Ann Rheum Dis. 2017;76(2):355-63.

9. Takeuchi T, Yamanaka H, Tanaka Y, Sakurai T, Saito K, Ohtsubo $\mathrm{H}$, et al. Evaluation of the pharmacokinetic equivalence and 54-week efficacy and safety of CT-P13 and innovator infliximab in Japanese patients with rheumatoid arthritis. Mod Rheumatol. 2015;25(6):817-24.

10. Tanaka Y, Yamanaka H, Takeuchi T, Inoue M, Saito K, Saeki Y, et al. Safety and efficacy of CT-P13 in Japanese patients with rheumatoid arthritis in an extension phase or after switching from infliximab. Mod Rheumatol. 2017;27(2):237-45. 
11. Jorgensen KK, Olsen IC, Goll GL, Lorentzen M, Bolstad N, Haavardsholm EA, et al. Switching from originator infliximab to biosimilar CT-P13 compared with maintained treatment with originator infliximab (NOR-SWITCH): a 52-week, randomised, double-blind, non-inferiority trial. Lancet. 2017;389(10086):2304-16.

12. Abdalla A, Byrne N, Conway R, Walsh T, Mannion G, Hanly $\mathrm{M}$, et al. Long-term safety and efficacy of biosimilar infliximab among patients with inflammatory arthritis switched from reference product. Open Access Rheumatol. 2017;9:29-35.

13. Avouac J, Molto A, Abitbol V, Etcheto A, Salcion A, Gutermann $\mathrm{L}$, et al. Systematic switch from innovator infliximab to biosimilar infliximab in inflammatory chronic diseases in daily clinical practice: the experience of Cochin University Hospital, Paris, France. Semin Arthritis Rheum. 2018;47(5):741-8.

14. Germain V, Scherlinger M, Barnetche T, Schaeverbeke T, Federation Hospitalouniversitaire Acronim. Long-term follow-up after switching from originator infliximab to its biosimilar CT-P13: the weight of nocebo effect. Ann Rheum Dis. 2018 (E-pub ahead of print).

15. Glintborg B, Sorensen IJ, Loft AG, Lindegaard H, Linauskas A, Hendricks $\mathrm{O}$, et al. A nationwide non-medical switch from originator infliximab to biosimilar CT-P13 in 802 patients with inflammatory arthritis: 1-year clinical outcomes from the DANBIO registry. Ann Rheum Dis. 2017;76(8):1426-31.

16. Holroyd CR, Parker L, Bennett S, Zarroug J, Underhill C, Davidson B, et al. Switching to biosimilar infliximab: real world data in patients with severe inflammatory arthritis. Clin Exp Rheumatol. 2018;36(1):171-2.

17. Nikiphorou E, Hannonen P, Asikainen J, Borodina J, Kokko A, Paalanen K, et al. Survival and safety of infliximab bio-original and infliximab biosimilar (CT-P13) in usual rheumatology care. Clin Exp Rheumatol. 2019;37(1):55-9.

18. Kristensen LE, Alten R, Puig L, Philipp S, Kvien TK, Mangues MA, et al. Non-pharmacological effects in switching medication: the nocebo effect in switching from originator to biosimilar agent. BioDrugs. 2018;32(5):397-404.

19. Kim SK, Choe JY, Lee SS, Shin K. Body mass index is related with the presence of syndesmophyte in axial spondyloarthritis: data from the Korean College of Rheumatology BIOlogics (KOBIO) registry. Mod Rheumatol. 2017;27(5):855-61.

20. Park DJ, Choi SJ, Shin K, Kim HA, Park YB, Kang SW, et al. Switching profiles in a population-based cohort of rheumatoid arthritis receiving biologic therapy: results from the KOBIO registry. Clin Rheumatol. 2017;36(5):1013-22.

21. Seoul National University Hospital. Korean College of Rheumatology Biologics Registry (KOBIO). 2018. https://clinicaltrials. gov/ct2/show/NCT01965132. Accessed 05 Feb 2019.

22. Anderson J, Caplan L, Yazdany J, Robbins ML, Neogi T, Michaud $\mathrm{K}$, et al. Rheumatoid arthritis disease activity measures: American College of Rheumatology recommendations for use in clinical practice. Arthritis Care Res (Hoboken). 2012;64(5):640-7.

23. Felson DT, Anderson JJ, Boers M, Bombardier C, Furst D, Goldsmith C, et al. American College of Rheumatology. Preliminary definition of improvement in rheumatoid arthritis. Arthritis Rheum. 1995;38(6):727-35.

24. Hall WJ, Wellner JA. Confidence bands for a survival curve from censored data. Biometrika. 1980;67:133-43.

25. Favalli EG, Pregnolato F, Biggioggero M, Becciolini A, Penatti $\mathrm{AE}$, Marchesoni A, et al. Twelve-year retention rate of first-line tumor necrosis factor inhibitors in rheumatoid arthritis: reallife data from a local registry. Arthritis Care Res (Hoboken). 2016;68(4):432-9.

26. Neovius M, Arkema EV, Olsson H, Eriksson JK, Kristensen LE, Simard JF, et al. Drug survival on TNF inhibitors in patients with rheumatoid arthritis comparison of adalimumab, etanercept and infliximab. Ann Rheum Dis. 2015;74(2):354-60.
27. Hetland ML, Christensen IJ, Tarp U, Dreyer L, Hansen A, Hansen IT, et al. Direct comparison of treatment responses, remission rates, and drug adherence in patients with rheumatoid arthritis treated with adalimumab, etanercept, or infliximab: results from eight years of surveillance of clinical practice in the nationwide Danish DANBIO registry. Arthritis Rheum. 2010;62(1):22-32.

28. Zink A, Strangfeld A, Schneider M, Herzer P, Hierse F, Stoyanova-Scholz M, et al. Effectiveness of tumor necrosis factor inhibitors in rheumatoid arthritis in an observational cohort study: comparison of patients according to their eligibility for major randomized clinical trials. Arthritis Rheum. 2006;54(11):3399-407.

29. Mercer LK, Galloway JB, Lunt M, Davies R, Low AL, Dixon WG, et al. Risk of lymphoma in patients exposed to antitumour necrosis factor therapy: results from the British Society for Rheumatology Biologics Register for Rheumatoid Arthritis. Ann Rheum Dis. 2017;76(3):497-503.

30. Mercer LK, Regierer AC, Mariette X, Dixon WG, Baecklund E, Hellgren K, et al. Spectrum of lymphomas across different drug treatment groups in rheumatoid arthritis: a European registries collaborative project. Ann Rheum Dis. 2017;76(12):2025-30.

31. Ramiro S, Sepriano A, Chatzidionysiou K, Nam JL, Smolen JS, van der Heijde D, et al. Safety of synthetic and biological DMARDs: a systematic literature review informing the 2016 update of the EULAR recommendations for management of rheumatoid arthritis. Ann Rheum Dis. 2017;76(6):1101-36.

32. European Medicines Agency. Remsima Summary of Product Characteristics. 2019. https://www.ema.europa.eu/documents/ product-information/remsima-epar-product-information_en.pdf. Accessed 5 Feb 2019.

33. European Medicines Agency. Remicade Summary of Product Characteristics. 2018. https://www.ema.europa.eu/documents/ product-information/remicade-epar-product-information_en.pdf. Accessed 13 Dec 2018.

34. Gulacsi L, Brodszky V, Baji P, Kim H, Kim SY, Cho YY, et al. Biosimilars for the management of rheumatoid arthritis: economic considerations. Expert Rev Clin Immunol. 2015;11(Suppl 1):S43-52.

35. Brodszky V, Baji P, Balogh O, Pentek M. Budget impact analysis of biosimilar infliximab (CT-P13) for the treatment of rheumatoid arthritis in six Central and Eastern European countries. Eur J Health Econ. 2014;15(Suppl 1):S65-71.

36. Schulze-Koops H, Skapenko A. Biosimilars in rheumatology: a review of the evidence and their place in the treatment algorithm. Rheumatology (Oxford). 2017;56(suppl_4):iv30-iv48.

37. Yoo DH. The rise of biosimilars: potential benefits and drawbacks in rheumatoid arthritis. Expert Rev Clin Immunol. 2014;10(8):981-3.

38. Goll GL, Jorgensen KK, Sexton J, Olsen IC, Bolstad N, Haavardsholm EA, et al. Long-term efficacy and safety of biosimilar infliximab (CT-P13) after switching from originator infliximab: open-label extension of the NOR-SWITCH trial. J Intern Med. 2019;285(6):653-69.

39. Kim J, Ha D, Song I, Park H, Lee SW, Lee EK, et al. Estimation of cost savings between 2011 and 2014 attributed to infliximab biosimilar in the South Korean healthcare market: realworld evidence using a nationwide database. Int $\mathbf{J}$ Rheum Dis. 2018;21(6):1227-36.

40. Aladul MI, Fitzpatrick RW, Chapman SR. Impact of infliximab and etanercept biosimilars on biological disease-modifying antirheumatic drugs utilisation and NHS budget in the UK. BioDrugs. 2017;31(6):533-44.

41. Jha A, Upton A, Dunlop WC, Akehurst R. The budget impact of biosimilar infliximab $(\operatorname{Remsima}(\mathrm{R}))$ for the treatment of autoimmune diseases in five European countries. Adv Ther. 2015;32(8):742-56. 
42. Westhovens R, Yoo DH, Jaworski J, Matyska-Piekarska E, Smiyan $\mathrm{S}$, Ivanova D, et al. Novel formulation of CT-P13 for subcutaneous administration in patients with rheumatoid arthritis: initial results from a phase I/III randomised controlled trial. Ann Rheum Dis. 2018;77(THU0191).

43. Yoo D-H, Westhovens R, Ben-Horin S, Reinisch W, Schreiber $\mathrm{S}$, Ye BD, et al. Development of a subcutaneous formulation of CT-P13 (infliximab): maintenance subcutaneous administration may elicit lower immunogenicity compared to intravenous treatment. Arthritis Rheumatol. 2018;70(Abstract 2514).
44. Viola M, Sequeira J, Seica R, Veiga F, Serra J, Santos AC, et al. Subcutaneous delivery of monoclonal antibodies: how do we get there? J Control Release. 2018;286:301-14.

45. Hur JW, Choe JY, Kim DW, Kim HA, Kim SH, Kim WU, et al. Rheumatoid arthritis patients fulfilling Korean National Health Insurance reimbursement guidelines for anti-tumor necrosis factor-alpha treatment and comparison to other guidelines. Rheumatol Int. 2015;35(11):1817-23.

\section{Affiliations}

\section{Hyoun-Ah Kim ${ }^{1}\left[\right.$ Eunyoung Lee ${ }^{2,3} \cdot$ Sun-Kyung Lee ${ }^{4}$ Yong-Beom Park ${ }^{5}$ Young Nam Lee ${ }^{6}$ - Hee Jung Kang ${ }^{6}$. Kichul Shin ${ }^{4}$ (I)}

1 Department of Rheumatology, Ajou University School of Medicine, Suwon, Republic of Korea

2 Department of Biomedical Informatics, Ajou University School of Medicine, Suwon, Republic of Korea

3 Office of Biostatistics, Ajou Research Institute for Innovative Medicine, Ajou University Medical Center, Suwon, Republic of Korea
4 Division of Rheumatology, Seoul Metropolitan Government-Seoul National University Hospital Boramae Medical Center, Seoul, Republic of Korea

5 Department of Internal Medicine (Division of Rheumatology), Yonsei University College of Medicine, Severance Hospital, Seoul, Republic of Korea

6 Celltrion Healthcare Co. Ltd., Incheon, Republic of Korea 